\title{
Processos de investigação-ação nas pesquisas brasileiras sobre a formação inicial e/ou continuada de professores de Ciências/Biologia
}

\author{
Research-action processes in brazilian research on the initial and/or \\ continuing education of Science/Biology teachers
}

\begin{abstract}
Taciara Lais Borgartz
Acadêmica do curso de Licenciatura em Ciências Biológicas no Instituto Federal Farroupilha (IFFAR), Campus Santa Rosa. Bolsista da Fundação de Amparo à Pesquisa do Estado do Rio Grande do Sul

(FAPERGS).

IFFAR, Campus Santa Rosa, Santa Rosa, Rio Grande do Sul, Brasil. taciaraborgartz@gmail.com
\end{abstract}

\begin{abstract}
Dúbia Emmel
Professora da área de Pedagogia no Instituto Federal Farroupilha (IFFAR), Campus Santa Rosa. Professora colaboradora permanente do Programa de Pós-Graduação em Ensino de Ciências (UFFS).

Doutorado em Educação nas Ciências (UNIJUÍ); Mestrado em Educação nas Ciências (UNIJUÍ); Licenciatura em Pedagogia (SETREM). IFFAR, Campus Santa Rosa, Santa Rosa, Rio Grande do Sul, Brasil. rubia.emmel@iffarroupilha.edu.br
\end{abstract}

Resumo: Este artigo analisa a importância que há em utilizar a investigação-ação na formação inicial e/ou continuada de professores de Ciências/Biologia, para promover a reflexão sobre as práticas docentes na busca por constituir investigadores ativos-críticos. Nesse viés, o objetivo desta pesquisa é compreender as contribuições de pesquisas de artigos produzidos no país sobre a investigação-ação/pesquisa-ação, o ensino de ciências e formação inicial ou continuada de professores de Ciências e Biologia. A presente pesquisa apresenta uma abordagem qualitativa, através de análise do tipo documental, realizada no Scientific Electronic Library Online, abrangendo pesquisas dos anos de 2002 a 2018. As pesquisas encontradas são das regiões sul, sudeste e nordeste, sendo que a região sudeste apresenta um maior número de pesquisas. A partir disso, por meio dos trabalhados encontrados na base de dados analisada foi possível identificar, caracterizar e reafirmar a importância de processos de investigação-ação nas pesquisas brasileiras sobre a formação inicial e/ou continuada de professores de Ciências/Biologia.

Palavras-chave: Investigação-ação. Formação de professores.

Abstract: This article analyzes the importance of using action-research in the initial and/or continuing training of Science/Biology teachers, to promote reflection on practices in the search for constituting activecritical researchers. The objective of the study is to understand the contributions of articles researches produced in the country on investigation-action/research-action, science teaching and initial or continuing education of Science and Biology teachers. The present research presents a qualitative approach, through documentary type analysis, carried out in the Scientific Electronic Library Online, covering research from the years 2002 to 2018. The researches found are from the south, southeast and northeast regions, and the southeast region presents a greater number of searches. From this, through the works found in the analyzed database, it was possible to identify, characterize and reaffirm the importance of action-research processes in brazilian research about the initial and/or continuing education of Science/Biology teachers.

Keywords: Action-research. Teacher training. 
BORGARTZ, Taciara Lais; EMMEL, Rúbia. Processos de investigação-ação nas pesquisas brasileiras sobre a formação inicial e/ou continuada de professores de Ciências/Biologia

\section{Introdução}

A formação inicial e/ou continuada de professores de Ciências/Biologia pode, com base nos processos de investigação-ação, promover a constituição docente a partir da reflexão sobre as práticas (SCHÖN, 1992; ALARCÃO, 2011). Em cursos de formação inicial de professores, como já demonstram pesquisas na área (SHULMAN, 1986; PERRENOUD, 1993; GERALDI, FIORENTINI, PEREIRA, 2001), é necessário que haja o uso de uma prática de ensino efetiva, possibilitando aos licenciandos “(des/re)construir suas concepções sobre educação, a docência, e o currículo” (EMMEL, 2019, p. 41). Tais pesquisas indicam, sobre os cursos de licenciatura, que busca-se a atuação de um profissional em uma perspectiva que vá além da disciplina, que envolva também aspectos sociais, éticos e políticos do meio em que está inserido.

A investigação-ação, a partir da leitura em Carr e Kemmis (1986), trata do currículo como "forma de constituir comunidades de investigadores ativos-críticos" (MION; SAITO, 2001, p. 19). Neste contexto os professores tornam-se investigadores de sua prática, pois a materialização dessa não depende exclusivamente da grade curricular, o que auxilia na construção da ciência educacional crítica.

Ressalta-se a importância do professor se basear em práticas que busquem envolver o pensamento e a reflexão, caracterizando "o ser humano como criativo e não como mero reprodutor de ideias e práticas que lhe são exteriores" (ALARCÃO, 2011, p. 44), transformando a escola em um espaço reflexivo, a partir do conceito de "epistemologia da prática", introduzido por Schön (1992). Essa prática na ação docente consiste na interação da ação com o pensamento que resulta na reflexão. Conforme esse autor, existem três aspectos nesse processo: reflexão na ação, reflexão sobre a ação e reflexão sobre a reflexão na ação (SCHÖN, 1992).

Considerando tais apontamentos, o objetivo desta pesquisa é compreender as contribuições de pesquisas de artigos produzidos no país sobre a investigação-ação/pesquisaação ${ }^{1}$, o ensino de ciências e formação inicial ou continuada de professores de Ciências e Biologia. A partir da base de dados Scientific Electronic Library Online (SCIELO) ${ }^{2}$ buscamos os artigos indexados que possibilitaram a constituição dos estilos e coletivos de pensamento que caracterizam a pesquisa do tema. Sendo assim, da análise textual discursiva emergiram categorias e proposições das quais foram criados em metatextos que constituem as linhas teóricas e

\footnotetext{
${ }^{1}$ Nesse artigo consideramos investigação-ação sinônimo de pesquisa-ação, por isso, optamos por utilizar investigaçãoação.

${ }^{2}$ Disponíveis no site: $\underline{w w w . s c i e l o . b r}$
} 
diferentes concepções acerca da investigação-ação/pesquisa-ação, presentes na base de dados analisada.

\section{Materiais e Métodos}

A presente pesquisa em Ensino de Ciências apresenta uma abordagem qualitativa (LÜDKE, ANDRÉ, 2001). Assim, trata-se de uma análise do tipo documental, realizada a partir de revisão da literatura na base de dados de artigos brasileiros indexados e disponíveis em meio eletrônico no SCIELO. Os estudos encontrados foram entre os anos de 2002 a 2018. A escolha por esse indexador de periódicos se deu em vista de que abrange diferentes áreas do conhecimento, possui coleções de revistas e artigos científicos disponíveis para consulta e download. Como critério de busca foram utilizados os termos: - ensino de ciências/biologia; - formação inicial e/ou continuada de professores de ciências/biologia; - pesquisa-ação e/ou investigação-ação.

Realizamos, a priori, a análise temática dos conteúdos (LÜDKE; ANDRÉ, 2001) dos artigos encontrados na base de dados. A identificação e classificação são apresentadas na sistematização (quadro-síntese) do Quadro 1: ano; título do artigo; autor(as/es); palavras-chave; instituição; local (município e estado), nome do periódico ou revista.

A posteriori foram realizadas leituras dos artigos, a fim de produzir as sínteses das pesquisas. Também foi realizada a busca de excertos e dos referenciais teóricos utilizados a partir dos enfoques: formação inicial ou continuada de professores de Ciências/Biologia, ensino de ciências e investigação-ação e/ou pesquisa-ação.

A análise da pesquisa foi realizada por meio dos princípios da Análise Textual Discursiva (ATD) (MORAES, 2003; MORAES; GALIAZZI, 2007). A ATD se estruturada por meio das seguintes etapas: unitarização, pela qual os textos são fragmentados de acordo com as interpretações e compreensões dos autores, processo do qual emergem unidades de significado; categorias temáticas, que se estabelecem nas relações entre as unidades de significado agrupadas de acordo com suas semelhanças semânticas; comunicação ou produção de metatexto, movimento pelo qual são elaborados textos descritivos e interpretativos sobre as categorias temáticas criadas.

As questões éticas de pesquisa foram respeitadas, uma vez que foram analisados trabalhos acadêmicos selecionados em base de dados de domínio público na $W e b 2.0$. 
BORGARTZ, Taciara Lais; EMMEL, Rúbia. Processos de investigação-ação nas pesquisas brasileiras sobre a formação inicial e/ou continuada de professores de Ciências/Biologia

\section{Análise dos dados: resultados e discussões}

O Quadro 1, abaixo exposto, apresenta os artigos indexados em meio eletrônico no SCIELO, e indica um baixo número de produções, visto que o país ainda não se destaca como referência em pesquisas na referida área. Com base na análise dos dados apresentados no quadro que foi realizada a ATD.

Sobressaem-se as revistas que constituem as bases de dados neste recorte temporal, sendo duas revistas da região sudeste: "Ciência \& Educação" (A1, A2, A3, A4, A5, A6, A7, A8, A10) e "Ensaio Pesquisa em Educação em Ciências" (A9). As pesquisas compõem os eixos das regiões Sul (A3, A8), Sudeste (A1, A2, A4, A5, A6, A7, A9, A10) e Nordeste (A7); prevalecendo a região sudeste.

Quadro 1 - Artigos sobre a investigação-ação na formação inicial e/ou continuada de professores de Ciências e Biologia.

\begin{tabular}{|c|c|c|c|c|c|}
\hline $\mathbf{A}$ & Ano & Título & Autores & Palavras-chave & IES \\
\hline A1 & 2002 & $\begin{array}{c}\text { A alfabetização científica e o } \\
\text { processo de ler e escrever } \\
\text { em séries iniciais: } \\
\text { emergências de um estudo } \\
\text { de investigação-ação. } \\
\end{array}$ & $\begin{array}{l}\text { Arlete Terezinha } \\
\text { Esteves Brandi; } \\
\text { Célia Margutti do } \\
\text { Amaral Gurgel. }\end{array}$ & $\begin{array}{l}\text { Leitura e escrita; } \\
\text { Alfabetização científica; } \\
\text { Educação em Ciências; } \\
\text { Formação continuada; } \\
\text { Investigação-ação. }\end{array}$ & UNIMEP \\
\hline A2 & 2003 & $\begin{array}{l}\text { A investigação-ação na } \\
\text { formação continuada de } \\
\text { professores de ciências. }\end{array}$ & $\begin{array}{c}\text { Maria Inês de Freitas } \\
\text { Petrucci dos Santos } \\
\text { Rosa; Roseli } \\
\text { Pacheco Schnetzler. }\end{array}$ & $\begin{array}{c}\text { Investigação-ação; Ensino } \\
\text { de Ciências; Parcerias } \\
\text { colaborativas; } \\
\text { Concepções de ensino. } \\
\end{array}$ & $\begin{array}{c}\text { UNICAMP/ } \\
\text { UNIMEP }\end{array}$ \\
\hline A3 & 2005 & $\begin{array}{l}\text { Em busca de um perfil } \\
\text { epistemológico para a } \\
\text { prática educacional em } \\
\text { educação em ciências. }\end{array}$ & $\begin{array}{c}\text { Rejane Aurora Mion; } \\
\text { José André Peres } \\
\text { Angotti. }\end{array}$ & $\begin{array}{l}\text { Programas de pesquisa; } \\
\text { investigação-ação; } \\
\text { formação inicial de } \\
\text { professores; reconstrução } \\
\text { racional. } \\
\end{array}$ & $\begin{array}{l}\text { UEPG/ } \\
\text { UFSC }\end{array}$ \\
\hline A4 & 2009 & $\begin{array}{c}\text { Construir com os } \\
\text { professores do } 2^{\circ} \text { ciclo } \\
\text { práticas letivas inovadoras: } \\
\text { um projeto de pesquisa } \\
\text { sobre o ensino do tema } \\
\text { curricular 'alimentação } \\
\text { humana'. }\end{array}$ & $\begin{array}{l}\text { Viviane Souza } \\
\text { Galvao; João Feliz } \\
\text { Praia. }\end{array}$ & $\begin{array}{l}\text { Alimentação humana; } \\
\text { Investigação-ação; } \\
\text { Ensino por investigação; } \\
\text { Formação de professores. }\end{array}$ & $\begin{array}{l}\text { UNESP/ } \\
\text { U.PORTO }\end{array}$ \\
\hline A5 & 2009 & $\begin{array}{c}\text { A pesquisa-ação em } \\
\text { educação ambiental: uma } \\
\text { experiência no entorno de } \\
\text { uma unidade de } \\
\text { conservação urbana. } \\
\end{array}$ & $\begin{array}{l}\text { Tania Maria Cerati; } \\
\text { Rosmari Aparecida } \\
\text { de Morais Lazarini. }\end{array}$ & $\begin{array}{c}\text { Educação Ambiental; } \\
\text { Pesquisa-ação; Unidades } \\
\text { de conservação; } \\
\text { Capacitação de } \\
\text { professores. }\end{array}$ & BGCI \\
\hline A6 & 2016 & $\begin{array}{c}\text { Pesquisa-Ação em } \\
\text { mestrados profissionais: } \\
\text { análise de pesquisas de um } \\
\text { programa de pós- }\end{array}$ & $\begin{array}{c}\text { Priscila de Souza } \\
\text { Chiste. }\end{array}$ & $\begin{array}{l}\text { Mestrado profissional; } \\
\text { Ensino; Metodologia da } \\
\text { pesquisa; Pesquisa-ação. }\end{array}$ & IFES \\
\hline
\end{tabular}




\begin{tabular}{|c|c|c|c|c|c|}
\hline & & $\begin{array}{l}\text { graduação em ensino de } \\
\text { ciências e de matemática. }\end{array}$ & & & \\
\hline A7 & 2017 & $\begin{array}{c}\text { Uma proposta de tipologia } \\
\text { para pesquisas de natureza } \\
\text { interventiva. }\end{array}$ & $\begin{array}{c}\text { Paulo Marcelo Marini } \\
\text { Teixeira; Jorge } \\
\text { Megid Neto. }\end{array}$ & $\begin{array}{l}\text { Pesquisa em educação; } \\
\text { Educação em ciências; } \\
\text { Métodos de pesquisa; } \\
\text { Pesquisa-ação. }\end{array}$ & $\begin{array}{l}\text { UESB/ } \\
\text { UNICAMP }\end{array}$ \\
\hline A8 & 2018 & $\begin{array}{c}\text { Estilos de pensamento de } \\
\text { professores da área de } \\
\text { Ciências da Natureza e o } \\
\text { processo de autonomia } \\
\text { compartilhada. }\end{array}$ & $\begin{array}{c}\text { Fabiana de Andrade } \\
\text { Leite; Lenir Basso } \\
\text { Zanon. }\end{array}$ & $\begin{array}{c}\text { Formação de professores; } \\
\text { Ensino de ciências; } \\
\text { Investigação-ação; } \\
\text { Coletivo de pensamento; } \\
\text { Autonomia. } \\
\end{array}$ & $\begin{array}{l}\text { UFFS/ } \\
\text { UNIJUÍ }\end{array}$ \\
\hline A9 & 2018 & $\begin{array}{l}\text { Pesquisa-ação e triangulação } \\
\text { metodológica na } \\
\text { investigação de percepções } \\
\text { de um grupo de alunos da } \\
\text { educação básica sobre o } \\
\text { ambiente. }\end{array}$ & $\begin{array}{c}\text { Carolina Paulo do } \\
\text { Nascimento; Maylta } \\
\text { Brandão dos Anjos; } \\
\text { Sonia Maria Ramos } \\
\text { de Vasconcelos. }\end{array}$ & $\begin{array}{c}\text { Pesquisa-ação; Educação } \\
\text { ambiental; Educação em } \\
\text { ciências; Grupo focal; } \\
\text { Triangulação } \\
\text { metodológica. }\end{array}$ & UFRJ/ IFRJ \\
\hline A10 & 2018 & $\begin{array}{l}\text { A formação de professores } \\
\text { de ciências a partir de uma } \\
\text { perspectiva de Educação } \\
\text { em Direitos Humanos: } \\
\text { uma pesquisa-ação. }\end{array}$ & $\begin{array}{l}\text { Roberto Dalmo } \\
\text { Varallo Lima de } \\
\text { Oliveira; Gloria } \\
\text { Regina Pessôa } \\
\text { Campello Queiroz. }\end{array}$ & $\begin{array}{l}\text { Pesquisa-ação; Ensino de } \\
\text { ciências; Educação em } \\
\text { direitos humanos; } \\
\text { Formação de professores. }\end{array}$ & UFU/ UERJ \\
\hline
\end{tabular}

Fonte: Autoras (2019). Nota: A (Artigos); IES (Instituições de Educação Superior); Siglas: UNIMEP (Universidade Metodista de Piracicaba); UNICAMP (Universidade Estadual de Campinas); UEPG (Universidade Estadual de Ponta Grossa); UFSC (Universidade Federal de Santa Catarina); UNESP (Universidade Estadual Paulista); U.PORTO (Universidade do Porto); BGCI (Botanic Gardens Conservation International); IFES (Instituto Federal do Espírito Santo); UESB (Universidade Estadual do Sudoeste da Bahia); UFFS (Universidade Federal da Fronteira Sul); UNIJUÍ (Universidade Regional do Noroeste do Estado do Rio Grande do Sul); UFRJ (Universidade Federal do Rio de Janeiro); IFRJ (Instituto Federal do Rio de Janeiro); UFU (Universidade Federal de Uberlândia); UERJ (Universidade do Estado do Rio de Janeiro).

A partir dos termos e critérios de busca foram encontrados dez artigos, dos quais dois (A1 e A2) são oriundos da UNIMEP, de Piracicaba, SP e dois (A2 e A7) são da UNICAMP, Campinas, SP, local com maior incidência de publicação. A3 é oriundo da UEPG, Ponta Grossa, PR e da UFSC, Florianópolis, SC, A4 da UNESP, Marília, SP e da U. PORTO, Porto, Portugal, enquanto que A5 é da BGCI, São Paulo, SP. A6, do IFES, Vitória, ES, a A7 é também da UESB, Jequié, BA. A8 é da UFFS, Cerro Largo, RS e da UNIJUÍ, Ijuí, RS, A9 da UFRJ, Rio de Janeiro, RJ e do IFRJ, Niterói, RJ e a A10 da UFU, Ituiutaba, MG e da UERJ, Rio de Janeiro, RJ.

Foram encontrados estudos entre os anos de 2002 e 2018, sendo que os anos de 2009 (A4 e A5) e 2018 (A8, A9 e A10) obtiveram maior número de pesquisas (cinco no total). A1 foi publicada no ano de 2002, A2 em 2003, A3 em 2005, A6 em 2016 e A7 em 2017. Ademais, as pesquisas encontradas são das regiões sul, sudeste e nordeste, sendo que a região sudeste apresenta um maior número de pesquisas (A1, A2, A4, A5, A6, A9 e A10). Destaca-se A4, que tem as instituições de origem em dois países, Brasil e Portugal. 
A partir da leitura em Contreras (1994) é possível reconhecer que existem três modelos de investigação-ação: a) prática, são processos de IA que visam a realização de valores intrínsecos à prática educacional, portanto implicam um processo de investigação e reflexão da prática à luz de seus propósitos e, vice-versa, dos fins ou valores à luz de eventos práticos (evidenciada em A1, A3, A4, A5, A6, A9, A10); b) técnica, tem a ver com os processos orientados por especialistas, nos quais os práticos realizam a investigação elaborada por esses e a direcionam à obtenção de resultados já pré-determinados, com uma clara preocupação produtivista ou eficiente (salientada em A2); c) emancipatória, por essa percepção tem-se em mente que nem sempre é possível perceber o que o modelo prático implica devido a restrições institucionais e ideológicas (presente em A7, A8).

\subsection{O que expressam as pesquisas sobre investigação-ação?}

Neste item apresentamos a análise realizada com base nas leituras de cada um dos artigos indexados, assim, identificamos o tema e o objetivo de cada estudo. A apresentação que segue tem o objetivo de contextualizar as temáticas de cada artigo e os processos de investigação-ação que demonstram.

A1 tem como tema: “A alfabetização científica e o processo de ler e escrever em séries iniciais: emergências de um estudo de investigação-ação”. O objetivo do estudo foi identificar processos e resultados no decorrer de atividades de alfabetização articulados com conhecimentos de Ciências, em parceria com uma professora, para identificar em que termos seria possível ocorrer o redimensionamento de sua prática pedagógica nesse ensino.

A2 tem como título: “A Investigação-ação na formação continuada de professores de Ciências". Essa pesquisa analisou um processo de investigação-ação ocorrido no contexto de um programa de formação continuada de professores de Ciências, no qual constituiu-se um grupo de professoras/pesquisadoras que assumiram a própria prática como referência para o desenvolvimento de diferentes níveis de investigação educativa.

Em A3 o tema é: "Em busca de um perfil epistemológico para a prática educacional em educação em ciências". Nesse trabalho é feita uma comparação entre programas de investigação científica em Lakatos (1978 e 1979) e programas de investigação-ação educacionais crítico-ativos, buscando elaborar o perfil epistemológico da prática educacional em ciências naturais, apontando que a ciência pode iluminar a prática docente, e os problemas existentes em ensinar e aprender. 
A4 aborda o tema: “Construir com os professores do $2^{\mathbf{o}}$ ciclo práticas letivas inovadoras: um projeto de pesquisa sobre o ensino do tema curricular 'alimentação humana'". A pesquisa teve como propósito divulgar um projeto de investigação que foi desenvolvido com professores do segundo ciclo das séries iniciais do Ensino Fundamental, no qual se utilizou uma metodologia do tipo investigação-ação.

A5 tem como título: “A pesquisa-ação em educação ambiental: uma experiência no entorno de uma unidade de conservação urbana”. A pesquisa apresenta a construção de um projeto de educação ambiental pelo qual se utiliza a metodologia da pesquisa-ação, e que teve como objetivo sensibilizar a comunidade relacionada à aplicação do projeto sobre a importância da conservação do ambiente.

A6 possui como tema: “Pesquisa-Ação em mestrados profissionais: análise de pesquisas de um programa de pós-graduação em ensino de ciências e de matemática". Teve o objetivo de apresentar reflexões sobre a importância da pesquisa-ação no contexto de Mestrados Profissionais em Ensino de Ciências e de Matemática. Traz o histórico e desafios de mestrados profissionais, e aborda a pesquisa-ação como uma possibilidade de abordagem investigativa na área de ensino. Aponta como desafio a necessidade de colocar em evidência, tanto nos mestrados profissionais quanto na pesquisa-ação, as relações entre teoria e prática.

A7 tem como tema: "Uma proposta de tipologia para pesquisas de natureza interventiva". A pesquisa estabelece reflexões sobre as Pesquisas de Natureza Interventiva (PNI) e sua aplicação no campo de pesquisa educacional, com especial atenção para aquelas produzidas na área de Educação em Ciências. Evidencia as múltiplas facetas assumidas pelas investigações articuladoras de ação e pesquisa, e, mais que isso, problematiza o uso vago e indiscriminado do termo pesquisa-ação. Com base em revisão de literatura, apresenta uma série de características para definição de projetos de pesquisa-ação, separando essa modalidade de outras possibilidades existentes entre as PNI.

A8 aborda "Estilos de pensamento de professores da área de Ciências da Natureza e o processo de autonomia compartilhada". Essa pesquisa objetivou analisar sentidos expressos pelos professores da área acerca do conceito de autonomia, a pesquisa delineou-se em um contexto formativo em que foram identificados dois estilos de pensamento: um conservador, que expressa um sentido de autonomia unilateral, e outro transformador, em que a autonomia é compreendida como um processo compartilhado.

A9 o tema é: "Pesquisa-ação e triangulação metodológica na investigação de percepções de um grupo de alunos da educação básica sobre o ambiente”. Essa investigação-ação foi utilizada para abordar diversos temas numa escola municipal do Rio de 
Janeiro sobre educação em ciências - a educação ambiental (EA). A pesquisa teve como objetivo obter um retrato de como os alunos percebiam sua relação com o ambiente.

A10 apresenta o tema: “A formação de professores de ciências a partir de uma perspectiva de Educação em Direitos Humanos: uma pesquisa-ação”. A pesquisa defende que a elaboração de uma disciplina, estruturada a partir de uma perspectiva de Educação em Direitos Humanos (EDH) e presente na formação inicial de professores de Ciências, poderia favorecer a reflexão dos licenciandos sobre seu papel como agentes socioculturais e políticos. Teve como objetivo a elaboração de uma disciplina que possibilitou, durante a formação inicial do professor de Ciências, uma abordagem baseada na perspectiva de EDH.

\subsection{Análise dos referenciais teóricos recorrentes na investigação-ação}

A partir da elaboração do Quadro 1 foram selecionadas as referências bibliográficas relacionadas à investigação-ação e pesquisa-ação de todos os artigos, e foi elaborado um novo quadro. Esses dados foram tabulados e os autores que apareceram mais de uma vez foram reunidos e organizados no Quadro 2. As referências estão organizadas de acordo com a sua recorrência nos artigos. 
BORGARTZ, Taciara Lais; EMMEL, Rúbia. Processos de investigação-ação nas pesquisas brasileiras sobre a formação inicial e/ou continuada de professores de Ciências/Biologia

Quadro 2 - Referências sobre investigação-ação mais frequentes nos artigos analisados

\begin{tabular}{|c|c|c|}
\hline Autor & Artigos & Referência \\
\hline \multirow{2}{*}{$\begin{array}{l}\text { CARR, W. \& } \\
\text { KEMMIS, S. }\end{array}$} & A1, A2, A3, A8 & $\begin{array}{l}\text { CARR, W.; KEMMIS, S. Teoria Crítica de la enseñanza - la investigación- } \\
\text { acción em la formación del profesorado. Barcelona: Martinez Rocca. } 1988 .\end{array}$ \\
\hline & A6, A7 & $\begin{array}{l}\text { CARR, W.; KEMMIS, W. Becoming critical education: knowledge and } \\
\text { action research. London: The Palmer Press, } 1986 .\end{array}$ \\
\hline \multirow{3}{*}{ ELLIOTT, J. } & A2 & $\begin{array}{l}\text { ELLIOTT, J. La investigación-acción en educación. Madri: Ediciones } \\
\text { Morata, } 1990 .\end{array}$ \\
\hline & A2 & $\begin{array}{l}\text { ELLIOTT, J. Recolocando a pesquisa-ação em seu lugar original e próprio. } \\
\text { Tradução de PEREIRA, E.M.A. In: Cartografias do trabalho docente - } \\
\text { professor(a)-pesquisador(a), GERALDI, C.M.; FIORENTINI, D. e } \\
\text { PEREIRA, E.M. (orgs). Campinas: Mercado das Letras, } 1998 .\end{array}$ \\
\hline & A4 & $\begin{array}{l}\text { ELLIOTT, J. El cambio educativo desde la investigación-acción. Madrid: } \\
\text { Morata, } 1990 .\end{array}$ \\
\hline \multirow[b]{2}{*}{ LEWIN, K. } & A3 & LEWIN, K. Problemas de dinâmica de grupo. São Paulo: Cultrix, 1978. \\
\hline & A9 & $\begin{array}{l}\text { LEWIN, K. Action research and minority problems. Journal of Social } \\
\text { Issues, n. 2, p. 34-46, } 1946 .\end{array}$ \\
\hline \multirow{3}{*}{$\begin{array}{l}\text { THIOLLENT, } \\
\text { M. }\end{array}$} & A5 & $\begin{array}{l}\text { THIOLLENT, M. Metodologia da pesquisa-ação. 14. ed. São Paulo: Cortez, } \\
2005 .\end{array}$ \\
\hline & A6, A7 & THIOLLENT, M. Metodologia da pesquisa-ação. São Paulo: Cortez, 2011. \\
\hline & A7 & $\begin{array}{l}\text {. Notas para o debate sobre pesquisa-ação. In: BRANDÃO, C. R. } \\
\text { (Org.). Repensando a pesquisa participante. São Paulo: Brasiliense, } 1999 . \\
\text { p. 82-103. }\end{array}$ \\
\hline \multirow{2}{*}{ BARBIER, R. } & A6, A10 & BARBIER, R. A pesquisa-ação. Brasília: Plano, 2002. \\
\hline & A7 & BARBIER, R. A pesquisa-ação. Brasília, DF: Líber, 2007. \\
\hline DIONNE, H. & A6, A7, A10 & $\begin{array}{l}\text { DIONNE, H. A pesquisa-ação para o desenvolvimento local. Brasília: Liber, } \\
2007 .\end{array}$ \\
\hline $\begin{array}{l}\text { EL } \\
\text { ANDALOUS } \\
\text { SI, K. } \\
\end{array}$ & A6, A7 & $\begin{array}{l}\text { EL ANDALOUSSI, K. Pesquisas-ações: ciências, desenvolvimento, } \\
\text { democracia. São Carlos: EdUfscar, } 2004 .\end{array}$ \\
\hline $\begin{array}{l}\text { FRANCO, M. } \\
\text { A.S. }\end{array}$ & A6, A7 & $\begin{array}{l}\text { FRANCO, M. A. S. Pedagogia da pesquisa-ação. Educação e Pesquisa, São } \\
\text { Paulo, v. 31, n. 3, p. 483-502, 2005. Disponível em: } \\
\text { <http://www.scielo.br/pdf/ep/v31n3/a11v31n3. pdf>. Acesso em: } 7 \\
\text { jun. 2016. }\end{array}$ \\
\hline $\begin{array}{l}\text { MIRANDA, } \\
\text { M. G.; } \\
\text { RESENDE, } \\
\text { A. C. A. } \\
\end{array}$ & A6, A7 & $\begin{array}{l}\text { MIRANDA, M. G.; RESENDE, A. C. A. Sobre a pesquisa-ação na } \\
\text { educação e as armadilhas do praticismo. Revista Brasileira de Educação, } \\
\text { Rio de Janeiro, v. 11, n. 33, p. 511-18, 2006. Disponível em: } \\
\text { <https://doi.org/10.1590/S1413-24782006000300011>. }\end{array}$ \\
\hline \multirow[b]{2}{*}{ MORIN, A. } & A7 & MORIN, A. Pesquisa-ação integral e sistêmica. Rio de Janeiro: DP\&A, 2004. \\
\hline & A7 & $\begin{array}{l}\text {. Notas para o debate sobre pesquisa-ação. In: BRANDÃO, C. R. } \\
\text { (Org.). Repensando a pesquisa participante. São Paulo: Brasiliense, } 1999 . \\
\text { p. 82-103. }\end{array}$ \\
\hline TRIPP, D. & A7, A9 & $\begin{array}{l}\text { TRIPP, D. Pesquisa-ação: uma introdução metodológica. Educação e } \\
\text { Pesquisa, São Paulo, v. 31, n. 3, p. 443-466, 2005. Disponível em: } \\
\text { <https://doi.org/10.1590/S1517-97022005000300009>. Acesso em: } 20 \\
\text { out. 2017. }\end{array}$ \\
\hline
\end{tabular}

Fonte: Autoras (2019).

A partir dos dados do Quadro 2 identificamos que os autores mais frequentes foram: CARR, W.; KEMMIS, S. (duas publicações, presente em seis artigos: A1, A2, A3, A6, A7, 
A8: total de citações 25); ELLIOTT, J. (dois artigos, três publicações diferentes: A2, A4: total de 8 citações); THIOLLENT, M. (três artigos, três publicações diferentes: A5, A6, A7: total de citações: 24); BARBIER, R. (três artigos, duas publicações: A6, A7, A10: total de citações: 27); DIONNE, H. (três artigos, a mesma publicação: A6, A7, A10: total de citações 9); LEWIN, K. (dois artigos, duas publicações: A3, A9: total de 6 citações); EL ANDALOUSSI, K. (dois artigos, a mesma publicação: A6, A7: total de 10 citações); FRANCO, M. A. S. (dois artigos, a mesma publicação: A6, A7: total de 15 citações); MORIN, A. (um artigo, duas publicações: A7: total de citações 10); TRIPP, D. (dois artigos, uma publicação: A7, A9: total de citações 9).

Os autores Carr e Kemmis (1998) foram identificados em 6 artigos. Observamos que a referência mais frequente é: Teoria Crítica de la enseñansa: la investigación-acción em la formación del profesorado, dessesautores, identificada em 4 artigos. A investigação-ação é tratada, por eles, como:

[...] uma forma de indagação autorreflexiva que compromete os participantes em situações sociais para melhorar a racionalidade e a justiça de suas próprias práticas, seus entendimentos das mesmas e as situações dentro das quais elas têm lugar (CARR; KEMMIS, 1998, p. 174, tradução nossa).

Dentre os objetivos essenciais para a construção da investigação-ação, os autores enfatizam dois objetivos principais - melhorar e interessar:

Em termos de melhoria, a pesquisa-ação aponta para três setores: primeiro, o aprimoramento de uma prática; segundo, à melhoria da compreensão da prática por quem a pratica; terceiro, à melhoria da situação em que essa prática ocorre. O objetivo do interesse anda de mãos dadas com o objetivo de melhorar. Os envolvidos na prática considerada devem intervir em todas as fases planejamento, ação, observação e reflexão - do processo de pesquisa-ação (CARR; KEMMIS, 1998, p. 177, tradução nossa).

A partir da obra, a IA está correlacionada à Ciência Educativa Crítica, para que "tenha o objetivo de transformar a educação; visa a mudança educacional” (CARR e KEMMIS, 1998, p. 168, tradução nossa). Objetivos como explicar (característica da abordagem positivista da pesquisa educacional) ou compreender (característica da abordagem interpretativa) são meros momentos do processo de transformação, e não propósitos suficientes em si mesmos.

Ainda conforme Carr e Kemmis (1998), a Ciência Educativa Crítica apresenta diferentes modos de pesquisa, abordando teoria e prática como forma de mudança educacional:

Diferentes modos de pesquisa educacional envolvem abordagens diferentes para a relação entre a teoria e a prática da educação e incorporam diferentes tipos de mudança educacional. Uma ciência educacional crítica, por outro lado, atribui os predicados de participação e colaboração à reforma educacional; levanta uma forma de pesquisa educacional concebida como uma análise crítica que visa a transformação de práticas educacionais, entendimentos educacionais e valores 
educacionais das pessoas envolvidas no processo, bem como as estruturas sociais e institucionais que definem o arcabouço de desempenho dessas pessoas (p. 168, tradução nossa).

O autor Thiollent foi identificado em 3 artigos, sendo o total de três publicações citadas. A partir dos ideais de Thiollent (2005 apud CERATI; LAZARINI, 2009), a pesquisa-ação é classificada:

como uma metodologia derivada da pesquisa social com base empírica, concebida e realizada em estreita associação com uma ação ou a resolução de um problema coletivo, e na qual pesquisadores e participantes representativos da situação ou problema estão envolvidos de modo cooperativo ou participativo (2009, p. 386).

As referências que tiveram a frequência 1:10 dos trabalhos analisados não foram citadas no quadro e estão disponíveis no Apêndice A; no total foram 18 referências. Dentre elas, constam 4 capítulos de livros, 4 livros, 5 artigos de revistas científicas, 3 teses de doutorado, 1 dissertação de mestrado.

Os artigos que apresentam maior número de referências de IA em ordem decrescente são: - A7, com doze referências; - A6, com oito referências; - A3, com sete referências; - A9, com seis referências; - A2, com cinco referências e A5, com quatro referências. Já os artigos com menor número são: A1, A4, A8 e A10, com três referências cada.

\section{Considerações finais}

A investigação-ação é fator importante na formação inicial e continuada do professor, pois caracteriza a reflexão pela prática e envolve aspectos sociais, éticos e políticos. Contudo, a partir do estudo aqui proposto, notamos que ainda é pouco utilizada em artigos científicos que abordam o tema formação, estando esses concentrados na região sudeste do país.

Destacam-se como principais autores de investigação-ação Carr e Kemmis (1988), cuja obra esteve presente em presentes em 6 dos artigos analisados, caracterizada como uma referência importante sobre o tema. Pelo embasamento nesses autores, a investigação-ação é tratada como uma indagação autorreflexiva, sendo que objetiva analisar as práticas para a reflexão e constituição docente.

Sendo assim, considerando a base de dados escolhida para a composição do corpus analítico foi possível identificar, caracterizar e reafirmar a importância de processos de investigação-ação nas pesquisas brasileiras sobre a formação inicial e/ou continuada de professores de Ciências/Biologia. Não obstante, ao vislumbrar professores reflexivos e escolas reflexivas, 
BORGARTZ, Taciara Lais; EMMEL, Rúbia. Processos de investigação-ação nas pesquisas brasileiras sobre a formação inicial e/ou continuada de professores de Ciências/Biologia

acreditamos na investigação-ação como um processo formativo necessário de ser realizado em pesquisas e estudos que possam, futuramente, auxiliar os (novos) professores em seu processo de formação, trazendo a importância de repensar a prática, transformando-a em ação-reflexão-criação.

\section{Referências}

ALARCÃO, I. Professores reflexivos em uma escola reflexiva. 8. ed. São Paulo: Cortez, 2011.

BARBIER, R. A pesquisa-ação. Brasília, DF: Líber, 2007.

BARBIER, R. A pesquisa-ação. Brasília: Plano, 2002.

CARR, W.; KEMMIS, W. Becoming critical education: knowledge and action research. London: The Palmer Press, 1986.

CARR, W.; KEMMIS, S. Teoria Crítica de la enseñanza: la investigación-acción em la for-mación del profesorado. Barcelona: Martinez Rocca. 1988.

CONTRERAS, J. D. La investigación en la acción. Cuadernos de Pedagogia, n. 224, Madrid: Morata, p. 7-31, abril, 1994.

DIONNE, H. A pesquisa-ação para o desenvolvimento local. Brasília: Liber, 2007.

EL ANDALOUSSI, K. Pesquisas-ações: ciências, desenvolvimento, democracia. São Carlos: EdUfscar, 2004.

ELLIOTT, J. El cambio educativo desde la investigación-acción. Madrid: Morata, 1990.

ELLIOTT, J. La investigación-acción en educación. Madri: Ediciones Morata, 1990.

ELLIOTT, J. Recolocando a pesquisa-ação em seu lugar original e próprio. Tradução de PEREIRA, E.M.A. In: Cartografias do trabalho docente - professor(a)-pesquisador(a), GERALDI, C.M.; FIORENTINI, D. e PEREIRA, E.M. (orgs). Campinas: Mercado das Letras, 1998.

FRANCO, M. A. S. Pedagogia da pesquisa-ação. Educação e Pesquisa, São Paulo, v. 31, n. 3, p. 483502, 2005.

LEWIN, K. Action research and minority problems. Journal of Social Issues, n. 2, p. 34-46, 1946.

LEWIN, K. Problemas de dinâmica de grupo. São Paulo: Cultrix, 1978.

LÜDKE, M.; ANDRÉ, M. E. D. A. Pesquisa em educação: abordagens qualitativas. São Paulo: Epu, 2001.

MORAES, R. Uma tempestade de luz: a compreensão possibilitada pela análise textual discursiva. Ciência e Educação: Bauru, SP, v. 9, n.2, p. 191-210, 2003.

MORAES, R.; GALIAZZI, M. C. Análise textual discursiva. Ijuí, RS: Ed. Unijuí, 2007. 
BORGARTZ, Taciara Lais; EMMEL, Rúbia. Processos de investigação-ação nas pesquisas brasileiras sobre a formação inicial e/ou continuada de professores de Ciências/Biologia

MORIN, A. Pesquisa-ação integral e sistêmica. Rio de Janeiro: DP\&A, 2004.

MORIN, A. Notas para o debate sobre pesquisa-ação. In: BRANDÃO, C. R. (Org.). Repensando a pesquisa participante. São Paulo: Brasiliense, 1999. p. 82-103.

PERRENOUD, P. Práticas pedagógicas, profissão docente e formação: perspectivas sociológicas. Lisboa: Dom Quixote, 1993.

SCHÖN, D. Formar professores como profissionais reflexivos. In: NÓVOA, A. (coord.). Os professores e sua formação. Lisboa: Dom Quixote, 1992, p. 77-90.

SHULMAN, L. Those who understand: the knowledge growths in teaching. Educational Reseacher, fev., p. 4-14, 1986.

THIOLLENT, M. Metodologia da pesquisa-ação. 14. ed. São Paulo: Cortez, 2005.

THIOLLENT, M. Metodologia da pesquisa-ação. São Paulo: Cortez, 2011.

TRIPP, D. Pesquisa-ação: uma introdução metodológica. Educação e Pesquisa, São Paulo, v. 31, n. 3, p. 443-466, 2005.

Recebido em: 05 mar. 2020/ Aprovado em: 25 jun. 2020

\section{Cite como}

\section{(ABNT NBR 6023:2018)}

BORGARTZ, Taciara Lais; EMMEL, Rúbia. Processos de investigação-ação nas pesquisas brasileiras sobre a formação inicial e/ou continuada de professores de Ciências/Biologia. Dialogia, São Paulo, n. 35, p. 214-227, maio/ago. 2020. Disponível em:

https://doi.org/10.5585/dialogia.n35.16753.

\section{American Psychological Association (APA)}

Borgartz, T. L., \& Emmel, R. (2020, maio/ago.). Processos de investigação-ação nas pesquisas brasileiras sobre a formação inicial e/ou continuada de professores de Ciências/Biologia. Dialogia, São Paulo, 35, p. 214-227. https://doi.org/10.5585/dialogia.n35.16753. 
BORGARTZ, Taciara Lais; EMMEL, Rúbia. Processos de investigação-ação nas pesquisas brasileiras sobre a formação inicial e/ou continuada de professores de Ciências/Biologia

Apêndice A - Referências sobre investigação-ação citadas uma vez nos artigos analisados

EBBUTT, D. \& ELLIOTT, J. Por qué deben investigar los profesores? In: ELLIOTT, John. La investigación-acción en Educación. Madrid: Ed. Morata, 1990. p. 176 - 190. (A1);

CONTRERAS, J.D. La investigación en la acción. Tema del mes. Cuadernos de Pedagogia, v. 224, abril. p. 7-19, 1994. (A2);

McNIFF, J. Action Research - Principles and Practice. Hong Kong: MacMillan Education. 1988. (A2);

ANGULO, J. F. Investigación-acción y curriculum: una nueva perspectiva en la investigación educativa. Investigación en la escuela, Sevilla. n. 11, p. 39-49, 1990. (A3);

DE BASTOS, F. P. Pesquisa-ação emancipatória e prática educacional dialógica em ciências naturais. 1995. Tese (Doutorado em Educação) Ifusp, Faculdade de Educação, Universidade de São Paulo, São Paulo, 1995. (A3);

KEMMIS, S.; MCTAGGART, R. Como planificar la investigación-acción. Barcelona: Laertes, 1988. (A3);

MION, R.; SAITO, C. H. (Org.). Investigạ̦ão-ação: mudando o trabalho de formar professores. Ponta Grossa: Planeta, 2001. (A3);

MION, R. A. Investigação-ação e a formação de professores em física: o papel da intenção na produção do conhecimento crítico. 2002. Tese (Programa de Pós-Graduação em Educação) - Centro de Educação, Universidade Federal de Santa Catarina, Florianópolis. (A3);

ROSA, M. I. F. P. S.; SCHNETZLER, R. P. A investigação-ação na formação continuada de professores. Ciência \& Educação, Bauru, v. 9, n. 1, p. 27-39, 2003. (A4);

GONZALES, L. T. V.; TOZONI-REIS, M. F. C.; DINIZ, R. E. S. Educação ambiental na comunidade: uma proposta de pesquisaação. Revista Eletrônica Mestrado em Educação Ambiental, Rio Grande, v. 18, 2007. Disponível em

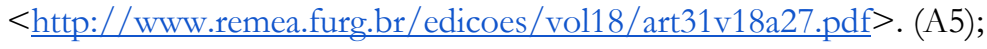

TOZONI-REIS, M. F. C. Pesquisa-ação: compartilhando saberes. Pesquisa e ação educativa ambiental. In: FERRARO JR., L.A. (Org.). Encontros e caminhos: formação de educadoras (es) ambientais e coletivo educadores. Brasília: Ministério do Meio Ambiente, 2005. Disponível em: < http://mma.gov.br/port/sdi/ea/og/pog/arqs/encontros.pdf.> (A5);

RICHARDSON, R. J. Pesquisa participante e pesquisa aşão: alternativas de pesquisa ou pesquisa alternativa. [S.l.: s.n., 2007]. Disponível em: <https://pt.scribd.com/doc/53078234/PESQUISA-PARTICIPANTE-E-PESQUISA-ACAO>. (A6);

GREENWOOD, D. J.; LEVIN, M. Reconstruindo as relações entre as universidades e a sociedade por meio da pesquisa-ação. In: DENZIN, N. K. et al. O planejamento da pesquisa qualitativa: teorias e abordagens. Porto Alegre: ArtMed, 2006. p. 91-113. (A7);

MCKERNAN, J. Curriculum action research: a bandbook of methods and resources for the reflective practitioner. London: Kogan Page, 1996. (A7);

GÜLLICH, R. I. C. O livro didático, o professor e o ensino de ciências: um processo de investigação-formação-ação. 2012. Tese (Doutorado em Educação nas Ciências) - Universidade Regional do Noroeste do Estado do Rio Grande do Sul, Ijuí, 2012. Disponível em: <http://bibliodigital.unijui.edu.br:8080/xmlui/handle/123456789/2043>. (A8);

ADELMAN, C. Kurt Lewin and the origins of action research. Educational Action Research, v. 1, n. 1, p. 7-24, 1993. (A9);

ENGEL, G. I. Pesquisa e Ação. Educar, Editora da UFPR, Curitiba, n. 16, p.181-191, 2000. (A9);

NASCIMENTO, C. P. O uso da pesquisa-ação para abordar um tema transversal na educação em ciências (educaşão ambiental) em uma escola municipal de Magé, RJ. Dissertação (Pós-graduação em Educação, Gestão e Difusão em Biociências), Universidade Federal do Rio de Janeiro, Rio de Janeiro, 2015 (A9). 